\title{
Best Possible Medication History for Hemodialysis Patients Obtained by a Pharmacy Technician
}

\author{
Marianna Leung, Joanne Jung, Wynnie Lau, Mercedeh Kiaii, and Beverly Jung
}

\begin{abstract}
Background: Outpatients undergoing hemodialysis are at high risk for adverse drug events. Limited resources make it challenging for pharmacists to routinely obtain a best possible medication history (BPMH).

Objectives: The primary objective was to determine whether, for patients undergoing hemodialysis, a pharmacy technician has the skills to obtain a BPMH that would allow a pharmacist to identify drug-related problems. The secondary objectives were to determine the number and types of medication discrepancies and drug-related problems identified and the time required by the technician to complete the BPMH.

Methods: All patients treated in the hemodialysis unit during the study period were included, except for those who required an interpreter or were unable to participate in an in-person interview. A single technician was taught how to interview patients according to a structured format. For each patient, the technician's BMPH was verified by a pharmacist. The agreement rate between technician and pharmacists was determined, along with the number and types of discrepancies and drugrelated problems identified.
\end{abstract}

Results: The technician interviewed 99 patients. Of the 1334 medication orders reviewed, the technician and pharmacists agreed on all but 15 (agreement rate 98.9\%). A total of 358 medication discrepancies were noted for 93 patients (3.8 discrepancies per patient). Of these, $210(59 \%)$ were undocumented intentional discrepancies, and 148 (41\%) were unintentional discrepancies (most commonly errors of commission). Of the 135 drug-related problems identified, the majority involved dosing problems or nonadherence. The technician required an average of $17 \mathrm{~min}$ for each interview.

Conclusion: An adequately trained technician was capable of interviewing patients to create a BPMH. A variety of medication discrepancies and drug-related problems were identified. Generation of a BPMH by a technician is a useful approach allowing pharmacists to identify drugrelated problems.

Key words: medication reconciliation, best possible medication history, hemodialysis, pharmacy technician

\section{RÉSUMÉ}

Contexte : Les patients externes sous hémodialyse sont à risque élevé d'événements indésirables liés aux médicaments. Avec les ressources limitées, il est difficile pour les pharmaciens d'obtenir systématiquement le meilleur schéma thérapeutique possible (MSTP).

Objectifs : Le principal objectif était de déterminer si, pour les patients sous hémodialyse, un technicien en pharmacie possède les compétences pour obtenir un MSTP qui permettrait au pharmacien d'identifier les problèmes reliés à la pharmacothérapie. Les objectifs secondaires étaient de déterminer le nombre et le type de différences relativement aux médicaments ainsi que les problèmes reliés à la pharmacothérapie identifiés et le temps requis par le technicien pour compléter le MSTP.

Méthodes : Tous les patients de l'unité d'hémodialyse au moment de l'étude ont été admis à celle-ci, à l'exception de ceux qui avaient besoin d'un interprète ou qui étaient incapables de participer à une entrevue en personne. Un seul technicien a été formé pour ménager une entrevue structurée avec les patients. Pour chaque patient, les MSTP obtenus par le technicien ont été vérifiés par un pharmacien. Le taux de correspondance entre les renseignements recueillis par le technicien et ceux validés par les pharmaciens a été déterminé et le nombre ainsi que les types de différences et les problèmes reliés à la pharmacothérapie identifiés ont été répertoriés.

Résultats : Le technicien a interviewé 99 patients. Des 1334 ordonnances de médicament analysées, le technicien et les pharmaciens étaient en désaccord pour 15 d'entre elles, soit un taux de concordance de 98,9\%. On a relevé 358 différences relativement aux médicaments chez 93 patients (3,8 différences par patient). De ces dernières, 210 (59\%) étaient des différences intentionnelles non consignées et 148 (41\%), des différences non intentionnelles (le plus souvent des erreurs de commission). Des 135 problèmes reliés à la pharmacothérapie identifiés, la plupart concernaient des problèmes de posologie ou de non-observance. Le technicien passait en moyenne 17 minutes par entrevue.

Conclusion : Un technicien adéquatement formé était en mesure d'interviewer les patients pour créer un MSTP. Une variété de différences relativement aux médicaments et de problèmes reliés à la pharmacothérapie ont été identifiés. La création d'un MSTP par un technicien est une approche utile permettant aux pharmaciens d'identifier les problèmes reliés à la pharmacothérapie.

Mots clés : bilan comparatif des médicaments, meilleur schéma thérapeutique possible, hémodialyse, technicien en pharmacie

[Traduction par l'éditeur] 


\section{INTRODUCTION}

$\mathrm{M}$ edication reconciliation has been identified as a focus area in the Safer Healthcare Now! initiative. Medication errors are common at each interface of care (i.e., admissions, transfers, and discharges). Adverse drug events and medication errors contribute from $20 \%$ to $72 \%$ of adverse events around the time of a hospital stay. ${ }^{1}$ In one study medication errors were reduced by more than $76 \%$ when medication reconciliation was implemented at these transition points. ${ }^{2}$ However, a comprehensive review of the medication regimen for every patient requires the commitment of substantial health care resources.

Outpatients undergoing hemodialysis have been identified as a population at high risk for adverse drug events. ${ }^{3,4}$ Accurate and timely reconciliation of medications taken at home with the current medication record in the hemodialysis unit is an important first step in ensuring that patients are receiving the best possible medications. In one study, discrepancies were found in the drug records of $60 \%$ of patients undergoing hemodialysis. ${ }^{5}$ Over a 5-month period, 113 discrepancies were noted for 38 patients, which put them at risk for adverse drug events $\left(56\right.$ [49.6\%]) and dosing errors (39 [34.5\%]). ${ }^{5}$ Because of limited health care funding, appropriate allocation of scarce resources is invaluable in targeting high-risk populations such as this one.

Although physicians and nurses assess patients during their dialysis sessions, neither discipline routinely focuses on medication use during investigations or treatment. These health care professionals already have considerable demands on their time for other matters related to the care of each hemodialysis patient. The patient-interviewing skills and medication knowledge of pharmacists would make them the most effective individuals to obtain a best possible medication history (BPMH). However, limited resources make it a challenge for pharmacists to routinely obtain a thorough medication history. Instead, pharmacists can best be utilized in identifying and resolving any drug-related problems from a medication list prepared by other personnel.

Pharmacy technicians are in a unique position to solicit a BPMH from patients. ${ }^{6,7}$ During their training period, technicians become familiar with a wide range of medications, including their dosage forms, strengths, and usual dosing schedules. ${ }^{8}$ Pharmacy technicians are also skilled in searching resources, such as the Compendium of Pharmaceuticals Specialities, ${ }^{9}$ to clarify therapies that are not commonly used in hospitals or to identify a product for a patient who is able to provide only a physical description. Also, pharmacy technicians have received training about nonprescription medications, which facilitates the identification of medications not in a prescription database such as the BC PharmaNet system. Most technicians are also familiar with methods of contacting community pharmacies to obtain additional history about a patient's medication use, possible nonadherence, and needs for special delivery systems. Although they have limited knowledge and education about pharmacology, pharmacy technicians have many skills that can facilitate the identification of medications. When working with pharmacists, technicians can use patientinterviewing and data-retrieval skills to clarify individual patients' drug therapy.

The primary objective of the study reported here was to determine whether a pharmacy technician could conduct interviews with hemodialysis patients or their caregivers to obtain the BPMH that would allow a pharmacist to identify drug-related problems. The secondary objectives were to determine the number and types of discrepancies encountered; the number and types of drug-related problems identified by the pharmacists on the basis of the information gathered by the pharmacy technician; and the time and associated costs of having a technician perform medication reconciliation.

\section{METHODS}

The study protocol was approved by the Providence Health Care Research Ethics Board.

All patients admitted to the hemodialysis unit at St Paul's Hospital in Vancouver, British Columbia, and not requiring an interpreter were included. Patients or caregivers who were unable to participate in an in-person interview were excluded. The study was conducted from May through August 2008. Patients were selected through routine practice on the unit: new admissions, recent discharges, and patients who had not had a recent medication review by the pharmacist. The patients were then divided into 2 groups: existing patients and new admissions.

The pharmacy technician (W.L.) received a 2-week training period in May 2008. The technician was taught the process of obtaining a BPMH in a structured format and was given the opportunity to observe and then to complete a certain number of medication histories under the direct supervision of a pharmacist. Once appropriate respect, empathy, courtesy, and competence had been demonstrated during supervised interviews, the technician was allowed to interact with patients independently. The technician was instructed to refer any patient inquiries and counselling needs to the pharmacist, who assessed the case and followed up with the patient according to the urgency and importance of the request.

The pharmacy technician's interviews were structured to obtain information about the patient's drug therapy at home. Information gathered included the name, dose, and administration schedule of all prescription, nonprescription, and complementary or alternative medications. The technician then compared the medication history obtained by interview with the current medication profile on file and identified any medications that were absent or prescribed in different dosages. Any such discrepancies were recorded on a discrepancy form specifically designed for this study (Appendix 1) and 
were brought to the attention of the pharmacist for further investigation. The discrepancies were categorized as unintentional discrepancies or undocumented intentional discrepancies. Unintentional discrepancies were defined as medication changes made either inadvertently or deliberately by the patient without the knowledge of the health care team. Undocumented intentional discrepancies were defined as medication changes made by another health care professional (e.g., the family physician, a specialist, or another team member) but not listed on the medication record of the hemodialysis unit. The unintentional discrepancies were subcategorized as omission, commission, wrong drug, wrong dose, or wrong frequency, as proposed by previous authors. ${ }^{10-12}$ Errors of omission were defined as medications being taken by the patient but not listed in the medication record, whereas errors of commission were defined as medications no longer being taken by the patient but still listed on the medication record. To determine the importance of these unintentional discrepancies in causing patient harm or clinical deterioration, the pharmacists were asked to categorize them into 3 classes, as proposed by Cornish and others. ${ }^{13}$ Class 1 discrepancies were those unlikely to cause patient discomfort or clinical deterioration. Class 2 discrepancies were those having the potential to cause moderate discomfort or clinical deterioration. Class 3 discrepancies were thought to have the potential to cause severe discomfort or clinical deterioration.

The pharmacists (M.L., J.J., and other relief clinical pharmacists) conducted interviews with the same patients, to verify the medication histories and thus to ensure that the technician was obtaining complete and accurate information, as well as to identify any drug-related problems. For each case, the pharmacist communicated drug-related problems to the prescriber if necessary. The drug-related problems were classified according to the 8 categories proposed by Strand and others ${ }^{14}$ : no valid indication for drug therapy, patient requires drug therapy but is not receiving it, patient is receiving the wrong drug or drug product, too little drug has been prescribed for the patient, too much drug has been prescribed for the patient, patient is not taking the prescribed drug appropriately, patient is experiencing an adverse drug reaction, and patient is experiencing a drug-drug, drug-food, or drug-laboratory interaction.

The technician was also instructed on proper use of the documentation forms, requirements for permanent documentation in the health care record, and methods to facilitate subsequent review by a pharmacist. At the time of the study, the pharmacy had a computer-generated medication order form to facilitate medication reconciliation and a monitoring form designed to document the medication history and identify unresolved drug-related problems. The technician was trained to use these 2 forms, as well as the discrepancy form (Appendix 1), for documenting the medication history, any discrepancies, and potential drug-related problems. The pharmacist reviewing the information documented on the monitoring form whether any drug-related problems had been identified and what action had been initiated to resolve them.

\section{Statistical Analysis}

For the primary end point, the rate of agreement between the technician and pharmacists for the medication history was recorded. The successful training of the technician to obtain the $\mathrm{BPMH}$ was used as an indicator of success. If such training could be accomplished for a single technician, it was assumed that other technicians could be trained in a similar manner to provide the same service. For the secondary end points, the numbers and types of discrepancies and drug-related problems were recorded. The time spent by the technician for the patient interview and the medication reconciliation process was recorded during the last month of the study to allow for sufficient training time and an additional adjustment period before data collection. The personnel cost for having a technician obtain the BPMH was also calculated.

\section{RESULTS}

A total of 99 patients were interviewed over the 4-month study period. The mean age of the patients was 67 years (range 19 to 96 years), and 55 (56\%) were men. The mean number of medications was 13.5 (range 5 to 23) per patient. Of the 1334 medication orders reviewed, the technician and pharmacists disagreed on 15 orders, an agreement rate of $98.9 \%$. Most discrepancies related to information about dosing. On average, the technician took $17 \mathrm{~min}$ (range 10 to 40) per interview.

The 6 new patients were excluded from the analysis of discrepancies because the unit had no existing medication records for new patients against which to compare the BMPH. For the 93 existing patients, a total of 358 discrepancies were identified, for an average of 3.8 discrepancies per patient. The average time since the last review of medications by a pharmacist was 158 days (range 7 to 359). Of the discrepancies identified, $210(59 \%)$ were undocumented intentional discrepancies and 148 (41\%) were unintentional discrepancies. Of the 148 unintentional discrepancies, 16 (11\%) were errors of omission, 65 (44\%) were errors of commission, 1 (1\%) involved the wrong drug, 24 (16\%) involved the wrong dose, and $42(28 \%)$ involved the wrong frequency. Of the 148 unintentional discrepancies, 126 (85\%) were considered unlikely to cause clinical deterioration or harm to patients (class 1), 21 (14\%) had a moderate risk (class 2), and 1 (1\%) had a high risk (class 3). The class 2 discrepancies included elevated hyperparathyroidism secondary to patients not taking phosphate binders or vitamin $\mathrm{D}$ analogues as prescribed and intradialytic hypotension secondary to patients taking antihypertensives before instead of after hemodialysis. The 
Table 1. Drug Classes Most Commonly Associated with Discrepancies

\begin{tabular}{lcc} 
Drug Class & No. (\%) of Discrepancies \\
& \multicolumn{2}{c}{$(\boldsymbol{n}=\mathbf{3 5 8 )}$} \\
\hline Gastrointestinal medications & 62 & $(17)$ \\
Analgesics & 46 & $(13)$ \\
Blood pressure medications & 39 & $(11)$ \\
Phosphate binders & 39 & $(11)$ \\
Vitamin D analogues & 26 & $(7)$ \\
\hline
\end{tabular}

single class 3 discrepancy involved the use of midodrine in a patient with systolic hypertension. The most common medication classes associated with discrepancies are listed in Table 1.

After comprehensive review by the pharmacists, 135 potential or actual drug-related problems were identified (Figure 1). Most commonly, the problems were related to drug dosing (too much or too little; 51 [38\%]) and medications not taken as prescribed (24 [18\%]).

\section{DISCUSSION}

This study demonstrated that a pharmacy technician, if adequately trained, can interview patients to obtain an accurate BPMH. The technician and the pharmacists disagreed on 15 of 1334 medication orders, for a disagreement rate of $1.1 \%$. Although there was not total agreement, the difficulty of obtaining consistent information from certain patients should be recognized. Such inconsistency would also be likely if the information was obtained by a health care professional other than the technician.

The hourly wage of a pharmacy technician is substantially lower than that of a pharmacist. The average interview time of 17 min translated to a total of $76.5 \mathrm{~h}$ and a cost of just over $\$ 1700$ to interview all of the patients on the unit $(n=270)$ at an hourly wage of $\$ 22.81 .{ }^{15}$ In contrast, the same interview time by the pharmacist would translate to a cost of $\$ 3100$ to $\$ 3700$ at an hourly pharmacist's wage of $\$ 41.39$ to $\$ 49.14$, depending on years of experience. ${ }^{16}$ For the purposes of this study, the pharmacists verified all medication histories obtained by the technician to ensure accuracy and completeness. If use of a pharmacy technician to obtain a BPMH was fully implemented, this would allow pharmacists extra time to perform other clinical activities, such as management of anemia or metabolic bone disease, as well as more in-depth interactions with patients needing resolution of drug-related problems; however, such an initiative would depend on whether extra funding is available to hire a pharmacy technician for this technical function.

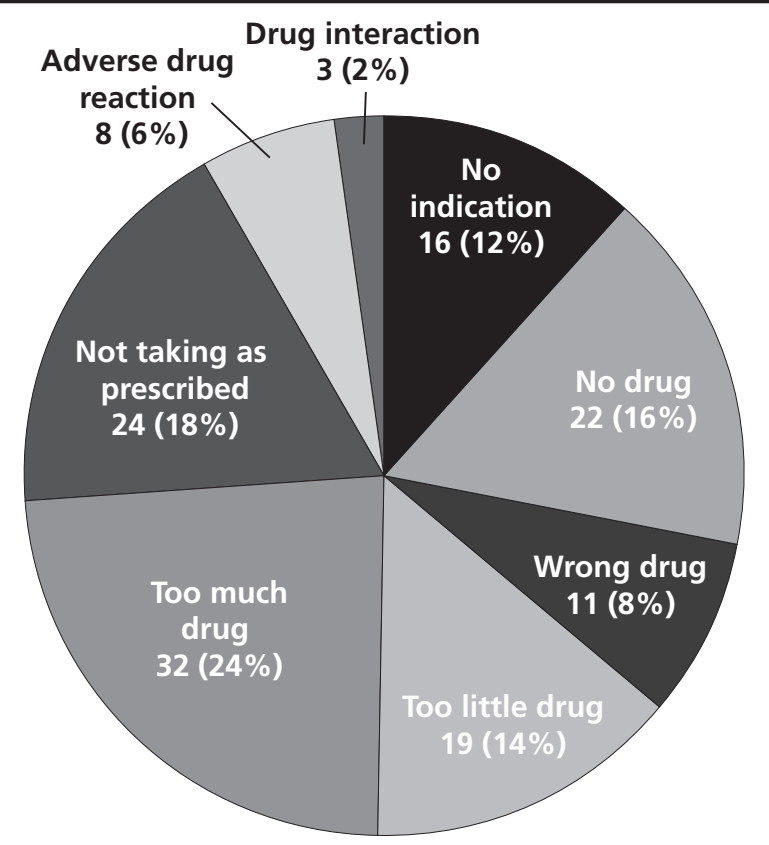

Figure 1. Classification of drug-related problems.

Numerous discrepancies were identified in the 93 existing patients interviewed. Almost 1 in 4 medications was different from that documented in the hemodialysis record, putting the patients at risk for adverse drug events. Similarly, Manley and others ${ }^{5}$ found 113 discrepancies in 38 hemodialysis patients, and errors of commission were also the most common discrepancy noted in that study. Previous studies of patients undergoing hemodialysis have suggested that they are taking an average of 10 to 12 medications. ${ }^{3,4}$ Furthermore, drug regimens may be changed frequently for patients with multiple concomitant conditions who are being treated by a variety of care providers. Any resulting discrepancies put patients at higher risk for adverse reactions, as therapeutic decisions and medication changes by the hemodialysis health care team are often based on the medication list available on the unit. Interacting or similar medications may be unknowingly prescribed by multiple health care providers. The patients in this study were taking an average of 13.5 medications and had discrepancies for an average of 3.9 medications, despite regular medication review by the pharmacists in the previous 5 months. These results further highlight the importance of more frequent performance of medication reconciliation within the unit.

Manley and others 5 found that adverse drug events were the most common drug-related problem, followed by drug dosing errors. However, those authors assumed that each discrepancy resulted in a drug-related problem; in the current study, the pharmacists interviewed the patients to identify actual and potential drug-related problems, irrespective of the discrepancies identified. Hence, there were discrepancies that 
did not result in drug-related problems and vice versa. There were an average of 1.4 drug-related problems per patient. The most common drug-related problems $(38 \%)$ related to taking too much or too little of a drug, and $18 \%$ were due to patients not taking medications as prescribed. In another study involving patients undergoing hemodialysis, Manley and others ${ }^{17}$ identified drug-related problems in $97.7 \%$ of patients, for an average of 3.6 problems per patient. The number of drug-related problems was positively correlated with the number of comorbidities. In collaboration with the health care team, pharmacists have an important role in addressing and resolving drug-related problems. Pharmacists could utilize additional time to further enhance patients' understanding of their medications and dosing regimens.

There were limitations to this study. Because of limited staffing resources and time constraints, only a relatively small number of patients were interviewed for this study. A comparative study design would provide more informative results. For example, medication interviews conducted by both a pharmacist and a technician in one study arm might be compared with medication interviews conducted by a pharmacist alone in the other. However, limited staffing resources prevented such a comparative study. In addition, the study was conducted over the summer, when most of the hemodialysis pharmacists were on vacation, and the pharmacy technician was a second-year pharmacy student working as a casual technician. However, all pharmacy technicians are hired on the basis of results of an interview, a typing test, and a standardized written examination testing knowledge of generic and brand names and abbreviations and accuracy with calculations. Once hired, all technicians go through a standardized 10-week orientation process in the various areas of the pharmacy department. The second-year pharmacy student had been hired and trained according to the standard procedure and had worked as a casual technician in the pharmacy department for over a year at the time of the study. Of note, a similar study from the same institution showed success in training an experienced technician to obtain the BPMH at the time of admission to the internal medicine and surgery units $(n=326$ patients), although the accuracy of the information obtained was not formally evaluated. ${ }^{18}$

In addition, because of the vacation schedule, a total of 6 pharmacists were involved in this study, of whom 2 were regular renal pharmacists (M.L., J.J.) who conducted over 85\% of the medication reviews. The vacation relief pharmacists had worked on the hemodialysis unit in the past and were well versed in the routine medication reconciliation and pharmaceutical care process on the unit. Moreover, the severity score was rated individually by the pharmacist involved with the medication review and not by a team of researchers; hence, there may have been inherent bias. However, any uncertainty in the scoring was reviewed by the primary investigator (M.L.).
Nevertheless, the results might have differed if the interviews had been performed by an experienced technician and regular hemodialysis pharmacists.

In conclusion, an adequately trained technician is capable of interviewing patients and preparing an accurate BPMH. In this population of patients undergoing hemodialysis, a number of discrepancies and drug-related problems were identified that put them at risk for adverse drug events. Having a technician prepare the BPMH is a useful first step in identification of drug-related problems by pharmacists or the health care team.

\section{References}

1. Vira T, Colquhoun M, Etchells E. Reconcilable differences: correcting medication errors at hospital admission and discharge. Qual Saf Health Care 2006;15(2):122-126.

2. Rozich JD, Howard RJ, Justeson JM, Macken PD, Lindsay ME, Resar RK. Standardization as a mechanism to improve safety in health care. Jt Comm J Qual Saf 2004;30(1):5-14.

3. Grabe DW, Low CL, Bailie GR, Eisele G. Evaluation of drug-related problems in an outpatient hemodialysis unit and the impact of a clinical pharmacist. Clin Nephrol 1997;47(2):117-121.

4. Kaplan B, Mason NA, Shimp LA, Ascione EJ. Chronic hemodialysis patients. Part I: Characterization and drug-related problems. Ann Pharmacother 1994;28(3):316-319.

5. Manley HJ, Drayer DK, McClaran M, Bender W, Muther RS. Drug record discrepancies in an outpatient electronic medical record: frequency, type, and potential impact on patient care at a hemodialysis center. Pharmacotherapy 2003;23(2):231-239.

6. Koch KE, Weeks A. Clinically orientated pharmacy technicians to augment clinical services. Am J Health Syst Pharm 1998;55(13):1375-1381.

7. Weber E, Hepfinger C, Koontz R, Cohn-Oswald L. Pharmacy technicians supporting clinical functions. Am J Health Syst Pharm 2005;62(23): 2466-2472.

8. Cameron T. Use of technicians to train nurses to help manage discharge medicines. Hosp Pharm 2006;13(10):379-380.

9. Repchinsky C, editor. Compendium of Pharmaceuticals and Specialities. Ottawa (ON): Canadian Pharmacists Association; 2009.

10. Lau HS, Florax C, Porsius AJ, De Boer A. The completeness of medication histories in hospital medical records of patients admitted to general internal medicine wards. Br J Clin Pharmacol 2000;49(6):597-603.

11. Beers MH, Munekata M, Storrie M. The accuracy of medication histories in the hospital medical records of elderly persons. I Am Geriatr Soc 1990;38(11):1183-1187.

12. Tam VC, Knowles SR, Cornish PL, Fine N, Marchesano R, Etchells E. Frequency, type and clinical importance of medication history errors at admission to hospital: a systematic review. CMAJ 2005;173(5):510-515.

13. Cornish PL, Knowles SR, Marchesano R, Tam V, Shadowitz S, Juurlink $\mathrm{DN}$, et al. Unintended medication discrepancies at the time of hospital admission. Arch Intern Med 2005;165(4):424-429.

14. Strand LM, Morley PC, Cipolle RJ, Ramsey R, Lamsam GD. Drug-related problems: their structure and function. DICP 1990;24(11):1093-1097.

15. Facilities subsector wage schedule 2006-2009. Burnaby (BC): Health Employee Union; [cited 2008 Oct 14]. Available from: http:// www.heu.org/\%7EDOCUMENTS/facwages2006-2010.pdf

16. Health science professional wage schedule in effect after the first pay period after April 1st, 2009. Vancouver (BC): Health Science Association of British Columbia, [cited 2009 Aug 31]. Available from: http://www.hsabc.org/ webuploads/files/member_services/collective_ agreements/hsp/WageSchFirstPayPeriodAfterApr12009.pdf

17. Manley HJ, McClaran ML, Overbay DK, Wright MA, Reid GM, Bender WL, et al. Factors associated with medication-related problems in ambulatory hemodialysis patients. Am J Kidney Dis 2003;41(2):386-393.

18. Remtulla S, Brown G, Frighetto L. Best possible medication history by a pharmacy technician at a tertiary care hospital. Can J Hosp Pharm 2009;62(5):402-405. 
Marianna Leung, BSCPharm, ACPR, PharmD, BCPS, BCPP, is a Clinical Pharmacy Specialist - Nephrology with the Pharmacy, Providence Health Care, Vancouver, British Columbia.

Joanne Jung, , BSCPharm, ACPR, was, at the time of the study, a clinical pharmacist with the Pharmacy, St Paul's Hospital, Providence Health Care, Vancouver, British Columbia. She is now the Regional Staff Education Pharmacist with Vancouver Coastal Health - Providence Health Care Pharmacy Services, Vancouver, British Columbia.

Wynnie Lau is a Pharmacy Technician with St Paul's Hospital, Providence Health Care, Vancouver, British Columbia. At the time of the study, she had completed her second year with the Faculty of Pharmaceutical Sciences, University of British Columbia.
Mercedeh Kiaii, MD, is Co-director of the Hemodialysis Unit at St Paul's Hospital, Providence Health Care, Vancouver, British Columbia.

Beverly Jung, MD, is Co-director of the Hemodialysis Unit at St Paul's Hospital, Providence Health Care, Vancouver, British Columbia.

\section{Address correspondence to:}

Dr Marianna Leung

Pharmacy Department

Providence Health Care

1081 Burrard Street

Vancouver BC V6Z 1Y6

e-mail: mleung@providencehealth.bc.ca

Appendix 1. Medication discrepancy form

Date

\section{PharmaNet \\ Medications brought in \\ Blister pack \\ Medication list}

Allergy

Last Med-Recon date:

\begin{tabular}{|c|c|c|c|c|c|c|c|}
\hline Medication & Discrepancy & 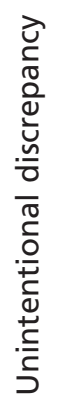 & 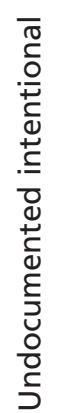 & 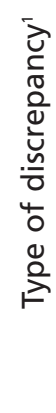 & $\begin{array}{c}\text { Significance } \\
\text { rank }^{2}\end{array}$ & $\begin{array}{l}\text { Action of } \\
\text { resolution }\end{array}$ & DRP \# ${ }^{3}$ \\
\hline & & & & & & & \\
\hline & & & & & & & \\
\hline & & & & & & & \\
\hline & & & & & & & \\
\hline & & & & & & & \\
\hline
\end{tabular}

1 : O - omission; C - commission; WDR - wrong drug; WDS - wrong dose; WFR - wrong frequency.

2 : Severity of discrepancies: class 1 were identified as those unlikely to cause patient discomfort or clinical deterioration, Class 2 were identified as those having the potential to cause moderate discomfort or clinical deterioration, and Class 3 were felt to have the potential to cause severe discomfort or clinical deterioration.

3 : DRPs: 1. No valid indication; 2. Requires a drug but not receiving; 3 . Receiving the wrong drug or product; 4 . Receiving too little drug; 5. Receiving too much drug; 6 . Not taking prescribed drugs appropriately/Nonadherence; 7. Experiencing adverse drug reaction; 8. Experiencing drug-drug, drug-food, or drug-laboratory test interaction. 